\title{
Desain Carbody Eksterior-Interior Light Rail Transit untuk Kota Palembang dengan Konsep Iconic dan Modern
}

\author{
Irfan Maulana Putra dan Agus Windharto \\ Departemen Desain Produk Industri, Fakultas Teknik Sipil dan Perencanaan, Institut Teknologi \\ Sepuluh Nopember (ITS) \\ e-mail: aguswind@prodes.its.ac.id
}

\begin{abstract}
Abstrak-Ditunjuknya kota Palembang menjadi salah satu host Asian Games 2018 memberikan dampak pada ditetapkannya percepatan pembangunan light rail transit melalui keputusan presiden tahun 2015. Hal ini mendukung kota Palembang yang memiliki misi untuk meningkatkan jaringan transportasi dan diharapkan mampu menyetarakan perekonomian dan pembangunan di berbagai wilayah kota Palembang. Namun, moda transportasi publik berbasis LRT merupakan sebuah hal yang baru bagi masyarakat khususnya warga kota Palembang dan sekitarnya. Perancangan ditujukan untuk memberikan alternatif desain LRT iconic dengan menggunakan morfologi ikan belida yang dikenal sebagai ikan khas kota Palembang. Hal ini didukung dengan identitas sebagai kota pinggiran sungai dengan jantung di sungai Musi. Pada interior, LRT dengan konsep modern yang interaktif sehingga sesuai dengan moda transportasi dengan jalur ekslusif untuk melayani pergerakan penumpang di kota Palembang dengan lancar dan cepat. Selain itu pentingnya akomodasi kebutuhan user akan memberi kelayakan yang optimal pada proyek LRT pertama di Indonesia ini. LRT Palembang diharapkan mampu menjadi awal yang baik dalam pembangunan moda transportasi publik berbasis rel di Indonesia dan dapat menjadi contoh yang baik untuk kota-kota lain, guna membantu perkembangan pembangunan wilayah negara Indonesia.
\end{abstract}

Kata Kunci-Carbody, LRT, Palembang.

\section{PENDAHULUAN}

$\mathrm{P}$ ALEMBANG merupakan salah satu kota besar di Indonesia yang memiliki tingkat perekonomian yang semakin meningkat. Berdasarkan masterplan percepatan dan perluasan pembangunan ekonomi Indonesia (MP3EI) 20112015, Koridor ekonomi wilayah Sumatera diharapkan menjadi pusat produksi dan pengolahan sumber daya alam sebagai cadangan energi bangsa. Salah satu misi dari pemerintah kota Palembang adalah dengan meningkatkan perekonomian melalui meningkatkan hubungan antar daerah melalui jejaring yang terkoneksi baik dari dalam maupun luar negeri. Jejaring tersebut tentunya harus didukung dengan meningkatnya sarana dan prasarana di dalam kota maupun akses yang sistem transportasi yang memadahi dan modern sehingga memberi citra positif terhadap kota.

Untuk mendukung misi yang telah dicanangkan pemerintah kota Palembang tersebut, Pemerintah Provinsi Sumatera Selatan berencana membangun Light Rail Transit (LRT) sebagai salah satu transportasi massal yang mampu mengangkut penumpang dengan jumlah sedang yang sesuai dengan kebutuhan penumpang untuk memudahkan aksesibilitas warga Palembang. Hal ini tentunya menjadi awal yang baik untuk perkembangan transportasi darat di kota Palembang yang di prediksi akan mengalami kemacetan di beberapa ruas jalan pada tahun 2018 [1].

Tabel 1.

Prediksi Tahun Kemacetan Ruas Jalan Kota Palembang [2]

\begin{tabular}{|c|c|}
\hline Ruas Jalan & Prediksi tahun macet \\
\hline JL. JENDRAL SUDIRMAN & 2029 \\
\hline JL. KAPTEN RIVAI & 2016 \\
\hline JL. SRIJAYA NEGARA & 2019 \\
\hline JL. DEMANG LEBAR DAUN & 2018 \\
\hline JL. BASUKI RAHMAT & 2015 \\
\hline JL. R. SUKAMTO & 2018 \\
\hline JL. RESIDEN H. ABDUL R. & 2038 \\
\hline JL. MAYOR ZEIN & 2018 \\
\hline JL. RE MARTADINATA & 2020 \\
\hline JL. YOS SUDARSO & 2019 \\
\hline JL. VETERAN & 2034 \\
\hline JL. RYACUDU & 2022 \\
\hline JL. GUBERNUR BASTARI & 2040 \\
\hline
\end{tabular}

Dengan adanya LRT yang beroperasi di kota Palembang, masyarakat diharapkan mulai dapat beralih dari kebiasaan menggunakan kendaraan pribadi yang mengakibatkan kemacetan dan polusi yang akan mengurangi efisiensi waktu transportasi berbagai kepentingan khususnya pergerakan perekonomian kota Palembang. Akan tetapi, LRT merupakan sarana transportasi baru dan tentunya masih awam bagi masyarakat kota Palembang mengingat LRT Palembang merupakan LRT pertama yang akan beroperasi di Indonesia. Oleh karena itu, perancangan dengan memerhatikan kebutuhan-kebutuhan khusus seperti konfigurasi, hingga akomodasi penyandang disable. Disisi lain, bentuk dan pewarnaan sebagai pengenalan corak khas daerah Palembang akan menjadi hal yang dikembangkan. 


\section{URAIAN PENELITIAN}

\section{A. Pengambilan Data}

Data pendukung perancangan diambil pada beberapa narasumber dan literatur. Data primer diperoleh melalui interview dari ahli dan dosen pembimbing Dr. Agus Windharto, DEA, Kementerian Perhubungan, BAPPEDA dan PT. INKA. Sedangkan data sekunder diperoleh melalui literatur terdahulu, buku penunjang pada perpustakaan dan internet.

\section{B. Subjek dan Objek Perancangan}

1. Subjek Perancangan : Desain eksterior dan interior Light rail transit dengan elevated exclusive track yang menghubungkan bandara Sultan Mahmud Badaruddin II Komplek Jakabaring kota Palembang dengan melalui pemberhentian pada 13 titik stasiun pada beberapa daerah strategis kota Palembang.

2. Objek Perancangan :Pada bagian eksterior LRT Yang meliputi konsep dari estetika maskara dan trainset. Dan pada bagian interior dengan optimasi konfigurasi tempat duduk, handrail, safety, ceiling, panel dinding dan komponen interior lainnya.

\section{Tahap Studi dan Analisis}

1. Analisis Calon Penumpang : Tinjauan ulang terhadap calon penumpang dengan memerhatikan karakteristik, aktifitas, dan kebutuhan guna menyelesaikan permasalahan yang akan terjadi pada carbody.

2. Analisis Benchmarking :Analisis benchmarking mengarah pada keberadaan moda transportasi sejenis yang ada untuk mendapatkan perbandingan yang sesuai dalam perancangan.

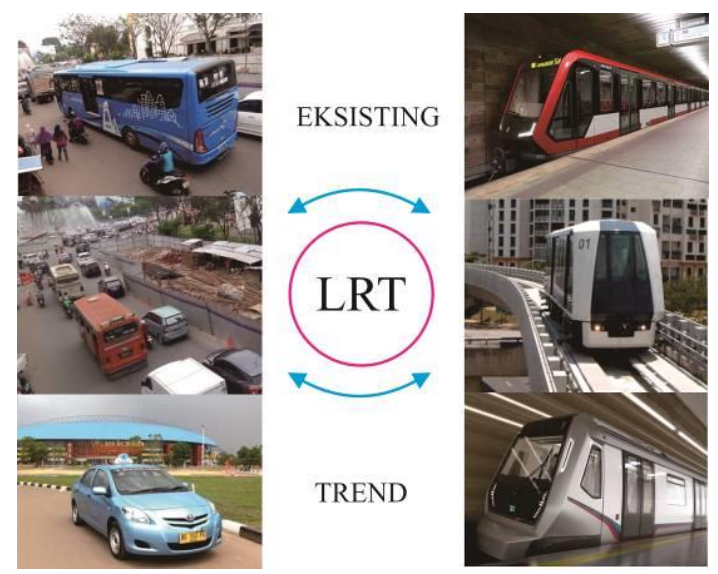

Gambar 1. Proyeksi Benchmarking Perancangan LRT [2] - [3].

3. Analisis Geometri : Analisis terhadap jalur, kebutuhan pintu, panjang dan lebar geometri, untuk mendapatkan dimensi rancangan yang sesuai untuk dikembangkan.

4. Analisis Blocking Area :Analisis terhadap positioning area komponen-komponen interior yang akan ditempatkan pada carbody sehingga memenuhi semua kebutuhan dan mendapatkan space interior yang efisien.

5. Study Ergonomi: Berguna untuk mengetahui segala hal yang berhubungan antara komponen dari carbody dan manusia sebagai user unttuk mendapatkan kenyamanan saat berada pada carbody LRT [4].

6. Analisis Lay out passanger analytical system: Pengaplikasian seluruh hal yang berhubungan dengan tataletak, ukuran, dan konfigurasi pada interior untuk mendapatkan desain interior yang optimal dan sesuai kebutuhan.

7. Study purwarupa dan trend : Styling board pada purwarupa kota Palembang yang digunakan sebagai konsep carbody LRT yang iconic untuk dijadikan acuan dan tema pada perancangan eksterior maupun interior.

8. Analisis Komponen dan produksi : bertujuan untuk mendapatkan hasil desain yang sesuai dengan komponen sistem produksi yang ada dan dapat digunakan dalam tahap engineering kedepannya

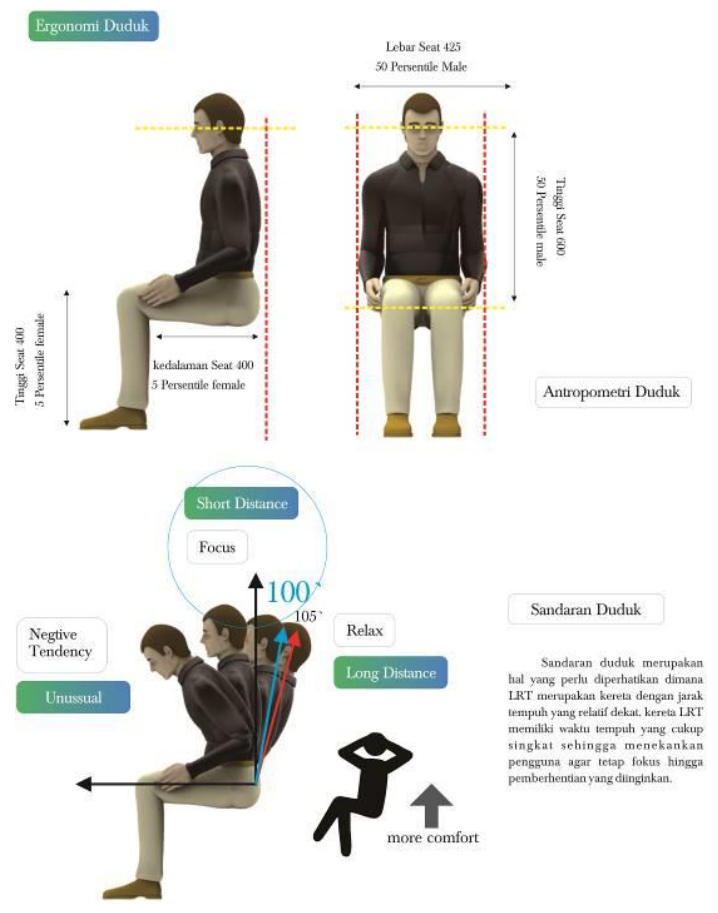

Gambar 2. Ergonomi duduk manusia.

\section{HASIL PENELITIAN}

\section{A. Analisis Bentuk dan Estetika}

Trend dan perkembangan bentuk angkutan transportasi modern berperan penting dalam pemilihan desain. Penggunaan bentuk yang simple namun mudah diingat akan menjadi nilai lebih pada sebuah maskara. Penerapan morfologi ikan belida pada maskara dengan mengambil bagian-bagian penting bentukan belida. Hal ini menjadikan sebuah maskara yang iconic dan menjadi kebanggaan kota Palembang.

Ikan Belida sendiri memiliki corak khas yang mudah diingat pada bentukan mulut dan dahi. Belida memiliki mulut yang lebih maju dan dahi dengan garis streamline. Dua hal tersebut menjadi acuan yang diterapkan pada bagian depan maskara. Selanjutnya dikombinasikan dengan lampu LED yang tajam untuk menambahkan kesan modern.

Sedangkan bentuk dan tampilan interior, mengacu pada trend yang lebih segmented dan clean untuk menghasilkan 
suasana yang lebih luas dan modern sesuai dengan kapasitas LRT sebagai sarana transportasi pubik yang akan mengangkut penumpang duduk dan berdiri.

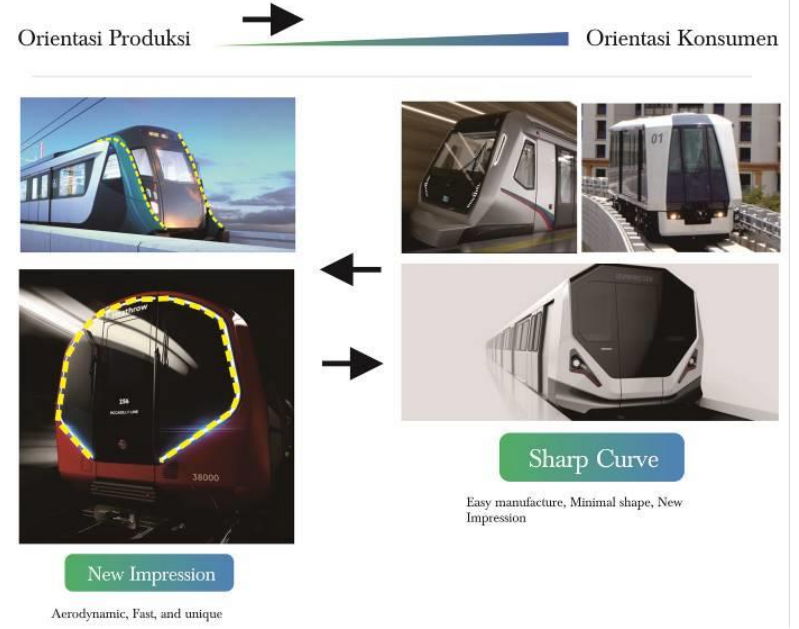

Gambar 3. Tren kereta metropolis [5].

B. Eksplorasi desain

Rendering Desain Akhir

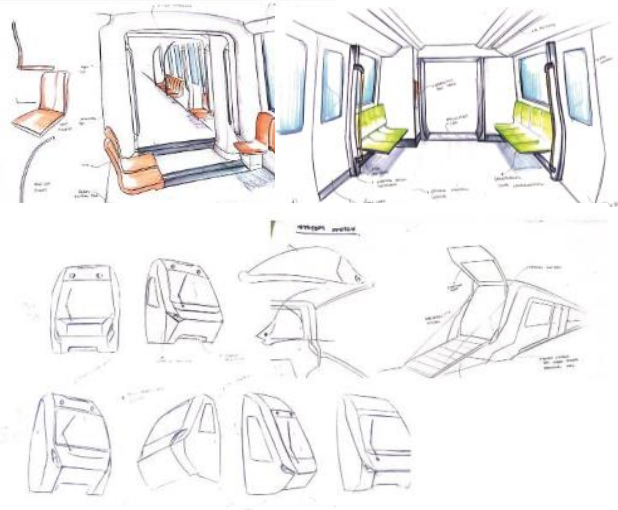

Gambar 4. Eksplorasi sketsa desain.
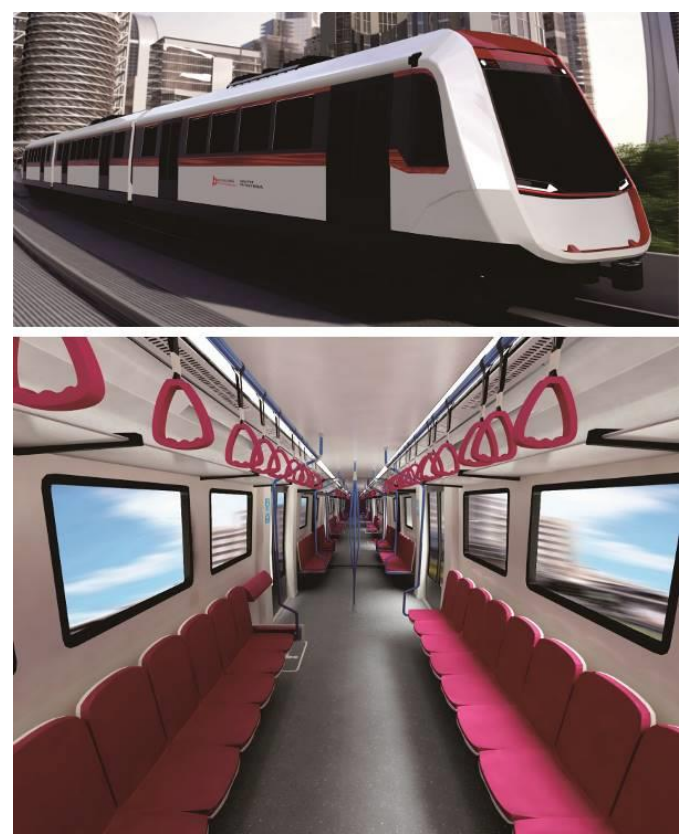

Gambar 5. 3D Digital rendering.
C. Study model berskala

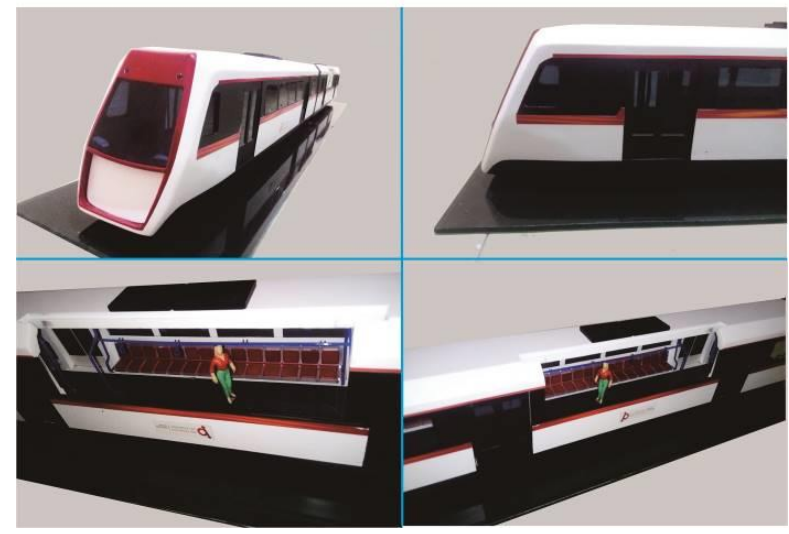

Gambar 6. Studi model berskala.

\section{KESIMPULAN/RINGKASAN}

\section{A. Kriteria Desain}

1. Bentuk: Desain carbody eksterior berupa maskara yang mengacu pada tren kereta modern serta bentuk morfologi dari ikan belida. Bentuk dasar ikan belida dan mengambil corak khas pada bagian mulut dan dahi ikan belida.

2. Dimensi Gerbong : Menggunakan dimensi panjang gerbong $16000 \mathrm{~mm}$ dan lebar $2650 \mathrm{~mm}$ dan tinggi $3500 \mathrm{~mm}$ yang disesuaikan dengan pembebanan pada konstruksi yang sesuai dalam perancangan.

3. Carbody : Konstruksi yang digunakan dalam penyusunan carbody adalah sistem aluminium ekstrusi sehingga mendapatkan beban yang lebih ringan dan sesuai dengan regulasi[6].

4. Bogie : Bolsterless bogie dengan lantai yang tinggi dan disesuaikan dengan lebar rel di Indonesia yaitu 1067 $\mathrm{mm}$.

5. Pintu : Menggunakan 4 pintu setiap gerbong agar memudahkan proses keluar masuk dan penyesuaian kapasitas penumpang carbody [7].

6. Konfigurasi : Penggunaan konfigurasi longitudinal dengan mempertimbangkan kapasitas penumpang duduk dan berdiri, serta akomodasi kebutuhan bagasi dan space penyandang disabilitas.

7. Kursi : Penggunaan kursi yang telah disesuaikan dengan ergonomi dan positioning yang sesuai dengan kenyamanan transportasi publik. Kursi ditopang oleh beberapa support sehingga memungkinkan penumpang meletakkan barang bawaan besar pada bawah kursi.

8. Bagasi ract : Adanya standing ract dan guna mengakomodasi penumpang dengan tujuan bandara yang memiliki barang bawaan lebih besar dibanding penumpang pada dalam kota.

9. Pencahayaan : Carbody interior menggunakan general lamp mengingat sarana transportasi publik modern yang membutuhkan pencahayaan yang terang. Hal ini meminimalisir berbagai tindak kejahatan yang dapat terjadi pada sarana transportasi LRT. 
10. Emergency tool : Penggunaan emergency tool box yang ditempatkan pada area strategis yang mudah dijangkau saat keadaan darurat yakni dekat pada pintu. Selain itu terdapat pula palu diantara kaca serta alat pemadam kebakaran carbody.

\section{B. Spesifikasi Teknis Desain}

\section{Kondisi umum :}

- lebar Rel : $1067 \mathrm{~mm}$

- radius putar minimum : $100 \mathrm{~m}$

- panjang lintasan total: 23 kilometer

- jumlah stasiun : 14 unit

- jarak antar stasiun: 600-2200 meter

- headway: 3 - 5 menit

2. Kondisi umum :

- panjang gerbong : $16000 \mathrm{~mm}$

- lebar gerbong (modul) : $2650 \mathrm{~mm}$

- tinggi gerbong dari atas rel : $3500 \mathrm{~mm}$

- jumlah rangkaian : 3 rangkaian (MC - TC - MC)

- jarak antar pusat boogie : $10500 \mathrm{~mm}$

- tinggi lantai kabin : $850 \mathrm{~mm}$ dari atas rel

- jumlah pintu per car : 4 buah double leaf door

- kapasitas per car :

MC : 121 orang duduk : 40 orang

berdiri : 81 orang ( 4 pax $/ \mathrm{m}$ )

TC $: 137$ orang

duduk : 48 orang

berdiri : 89 orang ( 4 pax $/ \mathrm{m}$ )

\section{DAFTAR PUSTAKA}

[1] BAPPENAS, "Draft final business case, Draft kajian akhir prastudi kelayakan report," Palembang, 2015.

[2] "Kuala Lumpur Mass Rapid Transit - Biggest Infrastructure Project in Malaysia," KVMRT Research. [Online]. Available: http://kvmrt.info/page/5/. [Accessed: 16-Feb-2018].

[3] Sydney Metro, "Sydney Metro," NSW. [Online]. Available: https://www.sydneymetro.info/about.

[4] J. Panero and M. Zelnik, Human Dimensions \&amp; Interior Space. Whitney Library of Design, 1979.

[5] Bombardier, "Bombardier Transportation," 2016. [Online]. Available: http://www.innotrans.de/media/inno/inno_images/inno_neuheiten/inno_n euheiten_2016/Bombardier_Transportation_2_.

[6] A. Kurniawan, "Desain Interior dan Eksterior KRD Bandara JuandaSurabaya," Surabaya, 2010.

[7] A. Suprayitno, "Desain Carbody Eksterior dan Interior Tramway sebagai Ikon Angkutan Massal Cepat Kota Surabaya," J. Sains dan Seni ITS, vol. 4, no. 2, 2015 